\title{
Analysis of 'Code red trauma calls' promoting the development of a novel cognitive aide for blood product resuscitation
}

\author{
Morton $\mathrm{S}^{1}$, Perritt $\mathrm{E}^{1}$, Gorry $\mathrm{J}^{2}$, Jones $\mathrm{C} \mathrm{PL}^{3}$ and Mercer $\mathrm{SJ}^{4 *}$ \\ ${ }^{1}$ Health Education North West School of Anaesthesia (Mersey), UK \\ ${ }^{2}$ Transfusion Practitioner, Aintree University Hospital NHS Foundation Trust, Liverpool, UK \\ ${ }^{3}$ Aintree University Hospital NHS Foundation Trust, Liverpool, UK \\ ${ }^{4}$ Aintree University Hospital NHS Foundation Trust, Liverpool, UK
}

\begin{abstract}
Background: The management of patients involved in complex trauma follows the principles of Damage Control Resuscitation; of which haemostatic resuscitation is a key pillar to this paradigm. A Code Red Trauma (CRT) Policy enables pre-hospital clinicians and hospital trauma team leaders to deliver blood and blood products to patients at the earliest opportunity upon their arrival to hospital.
\end{abstract}

Method/ Materials: The conduct of CRT practice over a 6-month period, in a busy MTC, located in the North West of England, was retrospectively examined to assess validity of CRT activation, blood product availability and blood product wastage.

Results: Between 1 January 2017 and 30 June 2017 there were 77 Code Red activations. Approximately two-fifths of activations were attributable to penetrating trauma (32/77), with activity spread throughout a 24-hour period. Subsequent retrospective analysis concluded that only 33 cases (42.9\%) actually met the criteria to be "Code Red" and warrant a declaration of a CRT with only 10 of these attributable to penetrating trauma. In total 43 units of blood products were wasted.

Conclusion: To address issues of excessive CRT activation and blood product wastage, we have increased engagement with our regional pre-hospital care services and developed cognitive aide models to assist our trauma team leader's critical decisions for blood product resuscitation.

\section{Introduction}

Trauma has been reported to be the leading cause of death and disability world-wide for persons under the age 35 years and accounts for approximately $10 \%$ of all deaths in general [1]. Haemorrhage is one of the leading causes of death in major trauma patients [2], with $50 \%$ of lethal outcomes occurring secondary to uncontrolled exsanguinating haemorrhage within the first 48 hours [3]. Coagulopathy associated with trauma exists in $25 \%$ of severely injured patients upon presentation to hospital [4].

Lessons learnt from recent conflicts in Iraq and Afghanistan have led to the adoption of key principles for Damage Control Resuscitation (DCR) when managing complex trauma [5,6]. DCR consists of three elements; permissive hypotension, damage control surgery and haemostatic resuscitation [7] with an emphasis on avoiding the 'lethal triad' of acidosis, coagulopathy and hypothermia. Haemostatic resuscitation involves the administration of PRBC, FFP and Platelets in a ratio of $1: 1: 1$ [8].

Major Haemorrhage Protocols (MHP) are also now widely adopted by Major Trauma Centres (MTC) in England. Whilst bleeding is uncontrolled blood product resuscitation is achieved by adhering to protocols that follow a set sequence of blood product administration. MHP streamlines the process of delivering DCR; haemostatic resuscitation, driving a coordinated response from all personnel involved [9]. Riskin reported a reduction in mortality from 45 to $19 \%$ after the implementation of a massive transfusion protocol for bleeding trauma patients in a local setting [10]. MHP implementation has resulted in an improved delivery of blood components and a reduction in the waste of blood products [11].

Despite the literature demonstrating benefits of adopting a MHP, there remains variation in clinical practice regards the:

- criteria for initiation

- role of point-of-care testing

- end points for termination

- indications for therapeutic adjuncts during resuscitation, for example use of calcium

The decision to initiate a MHP and terminate remains two most contentious areas of debate. Blood product transfusion is not a benign process and is fraught with risk [12]. Nevertheless, patient mortality

${ }^{\star}$ Correspondence to: Simon J Mercer, Consultant Anaesthetist, Aintree University Hospital NHS Foundation Trust, Longmoor Lane, Aintree, Liverpool, L9 7AL, UK, E-mail: simonjmercer@hotmail.com

Key words: damage control surgery, haemostatic resuscitation, trauma

Received: August 13, 2018; Accepted: August 22, 2018; Published: August 27, 2018 
after a massive haemorrhage significantly improves with decreased time between presentation and MHP activation, and also with decreased delays between MHP activation and the initiation of a MHP transfusion $[10,13,14,15]$.

To date several research studies have evaluated different scoring systems to predict the need for massive transfusion in varied trauma [16]. The American Society of Anesthesiologists, the American College of Surgeons (ACS), and the European Society for Advanced Bleeding Care in Trauma (ABC-Trauma) recommend the use of validated scoring systems to predict the need for massive transfusion [17]. The Trauma-Associated Severe Hemorrhage (TASH) and Assessment of Blood Consumption (ABC) are two common scoring systems [17-19].

The TASH score is more sophisticated derived from seven independent weighted variables; Systolic Blood Pressure (SBP), Heart Rate (HR), sex, haemoglobin, focused assessment with sonography for trauma (FAST), base excess, extremity or pelvic trauma. The ABC score is simple to calculate, formed from non-laboratory and non-weighted criteria easily assessed following patient arrival in the Emergency Department (ED); SBP < 90mmHg, HR > 120bpm, penetrating mechanism and positive fluid on FAST exam.

Nunez showed the ABC score to correctly predict the retrospective need for massive transfusion in $84 \%$ of cases, with a sensitivity of $75 \%$ and specificity of $86 \%$ [20]. The scoring system was further validated using trauma patient datasets recorded at 3 large level 1 trauma centers in the United States between 2006 and 2007. The validation data concluded that the ABC score to be $75-90 \%$ sensitive and $67 \%$ $88 \%$ specific with regard to its ability to retrospectively predict MT requirements within 24 hours of trauma [19]. Sophisticated systems such as the TASH Score that include higher numbers of variables have been reported to perform superior over simple non-weighted models [21].

Transferring validity of a scoring system to other trauma networks is challenging and not without risk. The application of the ABC-Score to aide critical decisions for massive transfusion in patients presenting to our MTC may not be best placed. We have immediate access to a CT scanner, as a result, the frequency of use for focused abdominal sonography in trauma (FAST) has significantly reduced. Furthermore, the majority of our trauma population are injured via blunt mechanism.

Standardisation of MHP initiation and DCR application will support the collection of robust clinical data, improving our understanding of these practices and their true impact. Prospective validations are required to improve the use and effectiveness of scoring systems.

To ensure blood and blood products are available at the earliest opportunity following patient arrival to our MTC ED a 'Code Red Trauma (CRT) Policy' has been developed and implemented. At our institution, a "Code Red Trauma" Call can be activated by the prehospital team or ED Trauma Team Leader (TTL). The following criteria [22] enables the TTL to activate a CRT, this is similar to other MTCs in England [11]:

- Traumatic Cardiac Arrest.

- Systolic Blood Pressure $<90 \mathrm{mmhg}$.

- Suspected Active Haemorrhage

- Visible Active haemorrhage

- Poor Response to Initial Fluid Resuscitation
In other regions across the UK, pre-hospital alerts are instigated when there is the suspicion or evidence of active haemorrhage, a systolic BP $<90 \mathrm{mmHg}$ or failure of blood pressure to respond to an intravenous fluid bolus [23]. Weaver and collagues [24] showed the effectiveness of the above criteria with $91 \%$ of pre-hospital 'Code Red' patients receiving blood product transfusion after arrival in hospital. Furthermore, patients declared 'Code Red', received a mean of 10.4 units PRBC transfusion in the first 24 hours. The Scottish Transfusion and Laboratory Support in Trauma Group (TLSTG) also have a unified National Pre-hospital Code Red protocol. Between June 1 $1^{\text {st }}, 2013$ and October $31^{\text {st }}, 2015$ there was 53 pre-hospital CRT activations. Subsequent analysis of this cohort concluded the above criteria to successfully predict a need for in hospital transfusion. Furthermore, it was reported CRT clinical practice did not lead to increased blood component discards [25].

At our institution, when a CRT is activated, the transfusion laboratory is contacted to provide a 'shock pack' consisting of 4 units of packed red blood cells (PRBC) and 4 units of fresh frozen plasma (FFP). To ensure blood products are available prior to patient arrival a designated 'runner' is sent immediately to collect the 4 units of PRBC, with defrosted FFP following on at the earliest opportunity. Subsequent shock packs contain platelets to enable a 1:1:1 transfusion of PRBC, FFP and platelets until control of bleeding is achieved following current evidence [26].

Once a pre-alert has been received, the trauma team (composition: Table 1) is activated (via specific criteria: Table 2), at the earliest opportunity all members of the team assemble in the resuscitation bay for an initial briefing by the trauma team leader (TTL) [27].

The initial team briefing is important as it outlines critical prehospital information, equipment required and to be prepared, plus an initial understanding of the TTLs mental model - what is expected to happen [28].

On arrival the trauma patient receives a primary systematic assessment with interventions completed in a horizontal fashion [29]. Survival during massive haemorrhage is critically dependent on rapid identification and control of the bleeding source(s). Every effort is taken to rule out other causes of shock, specifically addressing obstructive shock (tension pneumothorax, massive haemothorax and cardiac tamponade). Immediate access to limb tourniquets, topical haemostatic agents, compression bandages, pelvic and long bone splints, trained surgeons, chest drains and a 'thoracotomy tray' is vital.

Our institution uses the Belmont Rapid Infuser (Billerica, MA, USA), following a CRT activation the infuser is primed with crystalloid and blood products are only spiked following the instruction of the TTL after the patient arrives. The Belmont Rapid Infuser can deliver warmed PRBC and FFP at a maximum rate of $750 \mathrm{ml} / \mathrm{min}$. To prevent fluid overload, it is imperative to maintain awareness of fluid responsiveness and resuscitation state, repeated boluses of $250 \mathrm{ml}$ of blood product are given, this requires excellent communication skills amongst the trauma team. Speed and ease of blood product infusion places significant pressure on the hospital blood bank and wider logistic chains.

Only 7\% of the UK population are blood group O Neg [30], in 2014, NHS Blood and Transplant (NHSBT, the blood service for England and North Wales) issued three 'cautionary alerts' as blood stocks of $\mathrm{O}$ Neg fell to 3.5 days stock. Our hospital only stores two units of A-ve platelets in the blood bank, during DCR of a trauma patient this can be consumed quickly. To protect limited resources, at the earliest opportunity, blood product resuscitation is often guided by the use 
Table 1. The composition of a typical trauma team in the NHS and their roles

\begin{tabular}{|c|c|}
\hline Team Member & Role in the Trauma Team \\
\hline $\begin{array}{l}\text { Trauma Team Leader (TTL) } \\
\text { (Consultant) }\end{array}$ & $\begin{array}{l}\text { Trauma Team Leader } \\
\text { Brief the team } \\
\text { Delegate roles and responsibilities } \\
\text { Coordinate primary survey } \\
\text { Maintain situation awareness. }\end{array}$ \\
\hline $\begin{array}{l}\text { Primary survey doctor } \\
\text { (Emergency Medicine Specialty Trainee) }\end{array}$ & Perform the primary survey. \\
\hline $\begin{array}{l}\text { Anaesthetist } \\
\text { (Specialty Trainee 5-7, Post Final FRCA) }\end{array}$ & Responsible for airway management and advanced vascular access \\
\hline $\begin{array}{l}\text { Operator Department Practitioner } \\
\text { NHS Agenda for Change Band 5-6 }\end{array}$ & Assist the Anaesthetist \\
\hline $\begin{array}{l}\text { Scribe (Trauma Nurse Coordinator) } \\
\text { NHS Agenda for Change Band } 7\end{array}$ & Maintain a record of the events in the trauma bay \\
\hline $\begin{array}{l}\text { Emergency Medicine Nurse } 1 \text { (circulator) } \\
\text { NHS Agenda for Change Band } 5\end{array}$ & Support the trauma team \\
\hline $\begin{array}{l}\text { Emergency Medicine Nurse } 2 \text { (rapid infuser) } \\
\text { NHS Agenda for Change Band } 5\end{array}$ & $\begin{array}{l}\text { Check blood and blood products } \\
\text { Transfuse via the rapid infuser }\end{array}$ \\
\hline $\begin{array}{l}\text { Emergency Medicine Nurse } 3 \text { (rapid infuser) } \\
\text { NHS Agenda for Change Band } 5\end{array}$ & $\begin{array}{l}\text { Check blood and blood products } \\
\text { Transfuse via the rapid infuser }\end{array}$ \\
\hline $\begin{array}{l}\text { Runner (Health Care Assistant) } \\
\text { NHS Agenda for Change Band } 2\end{array}$ & $\begin{array}{l}\text { Collect blood and blood products from the transfusion laboratory and other equipment as } \\
\text { necessary. }\end{array}$ \\
\hline Orthopaedic Surgeon (Specialty Trainee 4-7) & Provide orthopaedic advice to the TTL \\
\hline General Surgeon (Specialty Trainee 4-7) & Provide general surgical advice to the TTL \\
\hline Radiographer & Undertake chest and pelvic $\mathrm{x}$-rays as required. \\
\hline
\end{tabular}

Table 2. Typical activation criteria for the Trauma Team in an NHS Major Trauma (taken from Kings College Hospital, Major Trauma Service: Information for Members of the Trauma Team).

\begin{tabular}{|c|c|}
\hline Traumatic event and one of the following: & $\begin{array}{ll}- & \text { Oxygen saturation }<90 \% \\
- & \text { Systolic arterial pressure }<90 \mathrm{~mm} \mathrm{Hg} \\
- & \text { Respiratory rate }<9 \text { or }>29 \mathrm{bpm} \\
\text { - } & \text { GCS }<14\end{array}$ \\
\hline Penetrating injury to & $\begin{array}{l}\text { Head } \\
\text { Neck } \\
\text { Chest } \\
\text { Abdomen } \\
\text { Pelvis }\end{array}$ \\
\hline \multicolumn{2}{|l|}{ All gunshot wounds } \\
\hline Fractures & $\begin{array}{l}\text { Open or depressed skull fractures } \\
\text { Pelvic fracture } \\
\text { Two or more proximal long bone fractures } \\
\text { Flail chest }\end{array}$ \\
\hline \multicolumn{2}{|l|}{ Traumatic amputation } \\
\hline \multicolumn{2}{|l|}{ Blast or crush injury } \\
\hline Major burns & $\begin{array}{l}-\quad>10 \% \text { total body surface area but lower threshold in child or elderly } \\
\text { - } \quad \text { Combination of burns and trauma }\end{array}$ \\
\hline Road traffic crash & 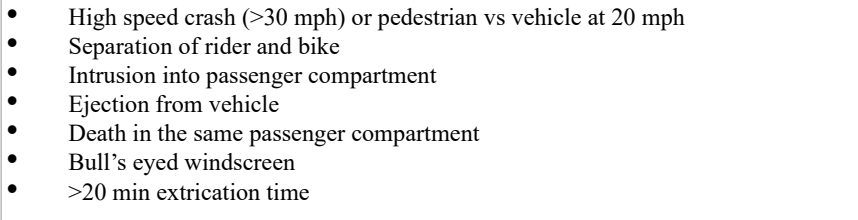 \\
\hline Falls & $\begin{array}{l}\text { - Height of }>3 \mathrm{~m} \\
\text { - } \\
\text { Paediatrics - consider the age and height of the child in relation to the height fallen }\end{array}$ \\
\hline \multicolumn{2}{|c|}{ Helicopter Emergency Medical Service (HEMS) transfer } \\
\hline Drowning/submersion & \\
\hline
\end{tabular}

of rotational thromboelastometry (RoTEM, Tem Innovations $\mathrm{GmbH}$, Basel). ROTEM guidance significantly reduces the number of blood products transfused, as well as blood loss, unfortunately there is currently no evidence supporting a positive effect on mortality $[31,32,33]$.

CRT patients are often the most complex cohort of patients presenting to UK MTCs, they require a consultant delivered service to lead a high performing team, make time critical decisions and implement timely interventions to optimizes outcome - this is the gold standard!

The conduct of CRT practice over a 6-month period, in a busy MTC, located in the North West of England, was retrospectively examined to assess the following:

- validity of CRT activation 
- blood product availability,

- blood product wastage

- grade of anaesthetic attendance amongst the trauma team.

\section{Methods}

A prospective record of all 'Code Red Trauma Calls' was compiled by the Lead Trauma Nurse Coordinator. Patient records and transfusion laboratory records were retrospectively analysed for the period of 1 January - 30 June 2017.

\section{Results}

Between 1 January 2017 and 30 June 2017 there were 77 Code Red activations. Of these, 55 were included in the Trauma Audit and Research Network return (https://www.tarn.ac.uk) and thus had New Injury Severity Score (NISS) and Injury Severity Score (ISS) calculations. Selected results are recorded in Table 3 and the initial destination of patients shown in Table 4. Code Red Trauma over a 6-month period at our institution revealed nearly two-fifths of activations were attributable to penetrating trauma, with activity spread throughout a 24-hour period. A subsequent retrospective analysis of all the patient data concluded that only 33 cases (42.9\%) actually met the criteria to be "Code Red" and warrant a declaration of a CRT only 10 of these were actually penetrating trauma that accounted for 32 cases in total (Table 3). The reasons for this were not specifically recorded, however possibilities are later discussed.

There was only documented evidence of blood being available prior to patient arrival in 22 cases (29\%), unfortunately the clinical notes were not robust enough to confirm if blood was present prior to arrival in just under $50 \%$ of trauma calls.

Over-activation of the MHP was the finding of a previous audit conducted in 2014 by the North West Regional Transfusion Committee (NW RTC) [34]. In 44\% of MHP activations a total of 2 units of PRBC or less was transfused with wastage levels reported as high for all components [34]. Unfortunately, this audit did not collect any specific details as to why wastage occurred, if this was thought to be avoidable

Table 3. Selected results

\begin{tabular}{|c|c|c|c|c|c|}
\hline \multicolumn{6}{|l|}{ Age of Patient } \\
\hline \multicolumn{2}{|c|}{$\begin{array}{c}\text { Average } \\
36.3 \text { years }\end{array}$} & & \multicolumn{2}{|c|}{$\begin{array}{l}\text { Median } \\
31 \text { years }\end{array}$} & $\begin{array}{c}\text { Range } \\
17-78 \text { years }\end{array}$ \\
\hline \multicolumn{5}{|l|}{ Mechanism of Injury } & Number of Patients \\
\hline \multicolumn{5}{|l|}{ Stabbing } & 32 \\
\hline \multicolumn{5}{|l|}{ Shooting } & 13 \\
\hline \multicolumn{5}{|l|}{ Pedestrian versus Car } & 7 \\
\hline \multicolumn{5}{|l|}{ Fall } & 12 \\
\hline \multicolumn{5}{|l|}{ RTC } & 8 \\
\hline \multicolumn{5}{|l|}{ Other } & 5 \\
\hline \multicolumn{3}{|l|}{ NISS } & $\begin{array}{c}\text { Average } \\
23.6\end{array}$ & $\begin{array}{c}\text { Median } \\
32\end{array}$ & $\begin{array}{c}\text { Range } \\
4-66\end{array}$ \\
\hline \multicolumn{3}{|l|}{ ISS } & $\begin{array}{c}\text { Average } \\
31.9\end{array}$ & $\begin{array}{c}\text { Median } \\
27\end{array}$ & $\begin{array}{c}\text { Range } \\
4-75\end{array}$ \\
\hline \multicolumn{5}{|l|}{ Time of Day } & Number of Patients \\
\hline \multicolumn{5}{|r|}{$0000-0800$} & 33 \\
\hline \multicolumn{5}{|r|}{$0800-1800$} & 24 \\
\hline \multicolumn{5}{|r|}{$1800-0000$} & 20 \\
\hline \multicolumn{6}{|c|}{\begin{tabular}{|l|l|l|l|l|l|} 
& Yes & No & Not Documented \\
\end{tabular}} \\
\hline \multicolumn{3}{|c|}{ Blood Available Prior to Arrival of Patient } & 22 & 19 & 36 \\
\hline Transfusion & 0 Units & 1-4 Units & 5-8 Units & 9-12 Units & $>12$ Units \\
\hline $\mathrm{O}$-ve PRBC & 35 & 25 & 9 & 6 & 2 \\
\hline X-Match PRBC & 68 & 9 & 2 & 0 & 0 \\
\hline FFP & 43 & 25 & 5 & 3 & 1 \\
\hline Transfusion & 0 Units & 1 Unit & 2 Units & 3 Units & 4 Units \\
\hline Cryoprecipitate & 67 & 7 & 3 & 0 & 0 \\
\hline \multirow[t]{2}{*}{ Platelets } & 64 & 0 & 12 & 0 & 1 \\
\hline & & & & & Total \\
\hline \multicolumn{5}{|l|}{ Blood Products Wasted } & 43 (11 patients) \\
\hline & & & Yes & No & Not Documented \\
\hline \multicolumn{3}{|c|}{ Anaesthetic Consultant Presence } & 31 & 23 & 23 \\
\hline \multirow{2}{*}{\multicolumn{3}{|c|}{ Emergency Intubation }} & \multicolumn{2}{|c|}{ Yes } & No \\
\hline & & & \multicolumn{2}{|c|}{35} & 42 \\
\hline
\end{tabular}


Table 4. Immediate destination of patient following trauma call

\begin{tabular}{|l|c|}
\hline Destination & Number \\
\hline Operating Theatre & 27 \\
\hline Interventional Radiology & 2 \\
\hline Critical Care & 10 \\
\hline Major Trauma Ward & 22 \\
\hline Other Hospital Ward & 5 \\
\hline Home & 2 \\
\hline Neurosciences Critical Care & 4 \\
\hline Death & 5 \\
\hline
\end{tabular}

or unavoidable. These findings are not unusual when comparing MHP practice with another busy UK MTCs [35].

\section{Discussion}

We have highlighted a number of issues regards the management of CRT patients within our institution and the wider Trauma Network. Although it is difficult to directly compare the results of a previous regional audit conducted three years earlier, despite implementation of a CRT policy at our Trust and within the regional ambulance service, clinical practice to reduce over-activation of MHP and minimise waste of blood products, appears to be no better. $57 \%$ of CRT activations in our study did not meet the correct criteria and clinical documentation failed to state reasons for this. We could not identify how many of the CRT activations were initiated by a pre-hospital team versus TTL.

Subsequent investigations revealed there to be no formal regional pre-hospital CRT policy. Ambulance clinicians were historically asked to "identify severe life threatening (peri-arrest) haemorrhage" via a pilot scheme without the development and support of a Clinical Standardised Operational Policy (CSOP). Without such a CSOP, pre-hospital CRT activation will have been subject to inter-operator variability dependent on wider understanding and previous clinical experience.

We fully acknowledged changing CRT practice required prehospital and hospital quality improvement projects! We have since increased engagement with our regional Ambulance Service and Trauma Network to develop a pre-hospital CSOP that aligns CRT practice from point of injury through to hospital ED reception, this includes the same activation criteria.

Situation awareness is defined as 'the perception of elements in the environment within a volume of time and space, the comprehension of their meaning, and the projection of their status in the near future' [36]. For 11 CRT activations, there was wastage of blood or blood products (43 units in total). Ideally it should be the TTL who gives decisions on whether to attach blood to the rapid infuser ('spike the blood'). The process of resuscitation is guided by both the TTL and anaesthetist, this requires good communication amongst the team, aided by good followership by all members of the trauma team [37]. During DCR it is important the TTL maintains good situation awareness particularly with reference to avoiding the waste of blood products by early decisions to return unrequired blood and blood products to the transfusion laboratory. Participation of senior clinicians in a trauma team facilitates early robust decision making [28], hence the aspiration for a consultant delivered service, this was documented in $40 \%$ of our cases.

The evidence supporting a CRT policy has been discussed, once a trauma patient arrives in ED a TTL does not need to identify the need for a massive transfusion but purely a need for blood product resuscitation? With no universally accepted method or algorithm to identify patient need for a massive transfusion, we believe the emphasis should actually be on early recognition and treatment of trauma patients who need immediate blood product resuscitation. Doing this maximizes oxygenation delivery, minimise acidosis, hypothermia, correct coagulopathy and support other critical interventions, more importantly it saves lives [15].

Not all trauma patients present with obvious exsanguinating bleeding or a history of significant blood loss at scene, note the latter has been proven to be wildly inaccurate [38]. The initial assessment of a time critical trauma patient can often be difficult. To fully appreciate the full extent of injuries sustained diagnostic imaging and other investigations are required. Unfortunately, a patient's clinical condition often demands time critical interventions, often at times when the TTL doesn't yet have all the information to complete a thorough risk versus benefit analysis. Vital signs including heart rate, blood pressure, oxygen saturation and respiratory rate may not always support a TTL's differential diagnosis. For example, a sympathetic response to trauma can mask the true haemodynamic status of profound hypovolaemia, with blood pressure readings being normal or elevated. For such patients with poly-trauma, who also require an emergency anaesthetic, pre-induction blood product resuscitation may be commenced in context to minimize risk of post induction hypotension, this can impact morbidity and mortality in patients with traumatic brain injury [39-41].

Clinical judgement (gestalt) has been reported to be valuable tool of the Emergency Physician [41]. The use of gestalt to guide MHP initiation has been shown to be $65.6 \%$ sensitive and $63.8 \%$ specific for predicting MT requirements. These values suggest clinical reasoning alone to be insufficient to independently guide initiation of a MHP, nevertheless it remains a valuable decision-making tool.

We have developed a novel cognitive aide model to support critical decision making for when to start blood product resuscitation in trauma patients (Figure 1). This has been designed as a hybrid to include frequent criteria used in validated massive transfusion scoring systems [20], with adjusted parameters to promote earlier decisions aligned with clinical gestalt. We have also created a traffic light triggering system to promote three specific actions; immediate blood product transfusion, discussion with members of the trauma team in context to the clinical situation and a delayed state which promotes continued vigilance for evolving clinical change and a prompt to send unwanted blood products back to the transfusion laboratory early. We have developed this aide to improve human performance, however as yet we have no feedback to offer for its use. It is our intention to first test pilot the use of this cognitive aide during trauma simulation training, if well received we will aim to assess its validity and will report our findings.

TTLs need to understand metacognition ("thinking about thinking and how we make decisions"). Kahneman described two modes of thought "System 1" and "System 2". System 1 is a fast, instinctive and emotional process - "gut instinct", whereas "System 2" is slower, more deliberative, and logical process - "critical thinking" [42].

Management of the major trauma patient presents the potential of a perfect storm for medical error! Here we are often exposed to novel, time critical, complex situations. The TTL must resist from purely using system one. This system is more likely to suffer from cognitive overloaded and is prone to cognitive bias when under pressure. The key to delivering optimum DCR is effective communication [42]. During the coordination of a command huddle, delivery of a snap brief or situation report system two is more likely to be active. Shared decisionmaking fosters better analytical, logical and critical thinking. TTLs are encouraged to step back and avoid direct contact with the patient to 


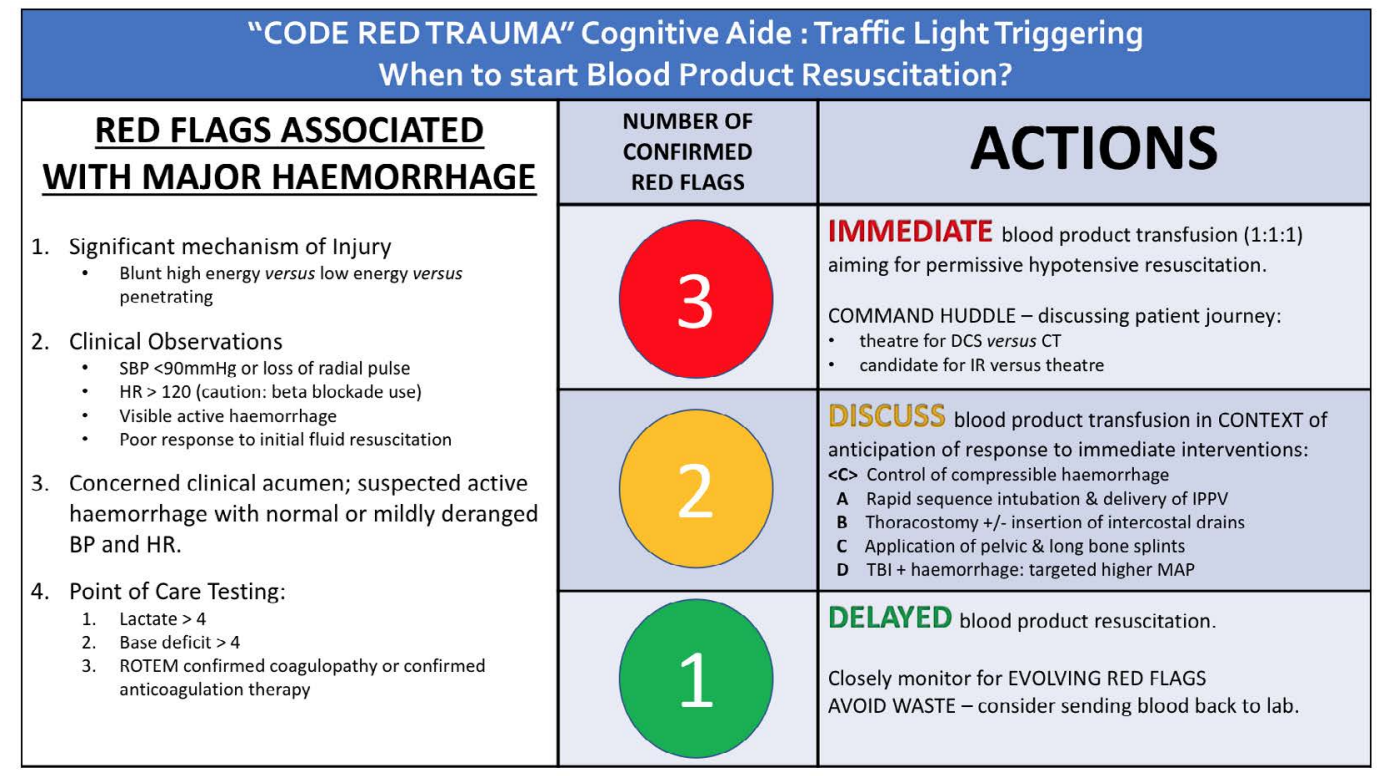

Figure 1. "CODE RED TRAUMA" Cognitive Aide: Traffic Light Triggering When to Start Blood Product Resuscitataion?

maintain overall situational awareness, this also serves a purpose to provide time and space to think analytically!

In reality, during the management of a complex major trauma patients, both systems are always active and our thoughts toggle between each mode. Understanding how we think promotes analysis of critical decisions before implementation - this may prevent a medical error! We cannot switch off system one, but we can reduce cognitive load by simulation team training, developing shared decision and nurturing followership $[37,43,44]$.

\section{Summary}

The development of a Code Red Trauma Policy allows the provision of blood and blood products in the trauma bay prior to the arrival of complex trauma patients and facilitates Damage Control Resuscitation.

Through the process of clinical audit, we have identified some key issues regards the management of CRT patients within our institution and the wider Trauma Network. Our results stimulated a number of quality improvement projects which we hope will be valuable to our institution and regional pre-hospital services. Understanding of metacognition in the context of managing major trauma was discussed. We strongly advocate simulation training to develop shared decision making and nurture followership.

Finally, we have developed a novel cognitive aide to support robust ED TTL decisions for when to start blood resuscitation. With increasing supporting evidence for the benefits of MHP, our focus was not to improve identifying patients who need a massive transfusion, but to promote early correct blood product resuscitation and preservation of limited resources by minimizing waste. We aim to validate our cognitive aide and will report our findings.

\section{Author Contribution}

Simon Morton: Identification of patients, literature search, data collection and review, revision of manuscript.

Elizabeth Perritt: Data collection and review, revision of manuscript.

Jan Gorry: Data collection and review, revision of manuscript.
Clinton PL Jones: Discussion, revision of manuscript, creation of Figure 1.

Simon J Mercer: Initial idea, first draft of manuscript and subsequent reviews.

\section{References}

1. Alberdi F, García I, Atutxa L, et al. (2014). Trauma and Neurointensive Care Work Group of the SEMICYUC. Epidemiology of Severe Trauma. Med Intensiva 38, 580588. [Crossref]

2. Gaunt C, Woolley T (2014) Management of Haemorrhage in Major Trauma. Continuing Education in Anaesthesia Critical Care \& Pain 14, 251-255

3. Kauvar DS, Lefering R, Wade CE (2006) Impact of hemorrhage on trauma outcome: an overview of epidemiology, clinical presentations, and therapeutic considerations. $J$ Trauma 60, S3-11. [Crossref]

4. Brohi K, Singh J, Heron M, Coats T (2003) Acute traumatic coagulopathy. $J$ Trauma 54: 1127-1130. [Crossref]

5. Mercer SJ, Tarmey NT, Woolley T, Wood P, Mahoney PF (2013) Haemorrhage and coagulopathy in the Defence Medical Services. Anaesthesia 68 Suppl 1: 49-60. [Crossref]

6. Hodgetts TJ, Mahoney PF, Kirkman E (2007) Damage control resuscitation. J R Army Med Corps 153: 299-300. [Crossref]

7. Jansen JO, Thomas R, Loudon MA, Brooks A (2009) Damage Control Resuscitation for Patients with Major Trauma. BMJ 338, 1436-1440. [Crossref]

8. Borgman MA, Spinella PC, Perkins JG, Grathwohl KW, Repine T, et al. (2007). The Ratio of Blood Products Transfused Affects Mortality in Patients Receiving Massive Transfusions at a Combat Support Hospital. J Trauma 63, 805-13. [Crossref]

9. Boutefnouchet T, Gregg R, Tidman J, Isaac J, Doughty H (2015) Emergency red cells first: Rapid response or speed bump? The evolution of a massive transfusion protocol for trauma in a single UK centre. Injury 46: 1772-1778. [Crossref]

10. Riskin DJ, Tsai TC, Riskin L, Hernandez-Boussard T, Purtill M, et al. (2009) Massive transfusion protocols: the role of aggressive resuscitation versus product ratio in mortality reduction. J Am Coll Surg 209: 198-205. [Crossref]

11. Khan S, Allard S, Weaver A, Barber C, Davenport R, et al. (2013). A Major Haemorrhage Protocol Improves the Delivery of Blood Component Therapy and Reduces Waste in Trauma Massive Transfusion. Injury 44, 587-92. [Crossref]

12. Clevenger B, Kelleher A. (2014). Hazards of Blood Transfusion in Adults and Children. Continuing Education in Anaesthesia Critical Care \& Pain 14, 112-118 
13. Holcomb JB, del Junco DJ, Fox EE, Wade CE, Cohen MJ, et al. (2013) The Prospective, Observational, Multicenter, Major Trauma Transfusion (PROMMTT) Study: Comparative Effectiveness of a Time-Varying Treatment with Competing Risks. JAMA Surg 148, 127-136. [Crossref]

14. Wang H, Umejiego J, Robinson R, Schrader CD, Leuck J, et al. (2016) A Derivation and Validation Study of an Early Blood Transfusion Needs Score for Severe Trauma Patients. J Clin Med Res 8, 591-597. [Crossref]

15. Meyer DE, Vincent LE, Fox EE, O'Keeffe T, Inaba K, et al. (2017). Every minute counts: time to delivery of initial massive transfusion cooler and its impact on mortality. J Trauma Acute Care Surg 83, 19-24. [Crossref]

16. Tonglet ML (2016) Early Prediction of Ongoing Hemorrhage in Severe Trauma: Presentation of the Existing Scoring Systems. Arch Trauma Res 5: e33377. [Crossref]

17. Foster JC, Sappenfield JW, Smith RS, Kiley SP (2017) Initiation and Termination of Massive Transfusion Protocols: Current Strategies and Future Prospects. Anesth Analg 125: 2045-2055. [Crossref]

18. Maegele M (2009) Frequency, risk stratification and therapeutic management of acute post-traumatic coagulopathy. Vox Sang 97: 39-49. [Crossref]

19. Cotton BA, Dossett LA, Haut ER, Shafi S, Nunez TC, et al. (2010). Multicenter validation of a simplified score to predict massive transfusion in trauma. J Trauma. 69: S33-S39. [Crossref]

20. Brockamp T, Nienaber U et al. (2012). Predicting On-going Haemorrhage and Transfusion Requirement After Severe Trauma: A Validation of Six Scoring Systems and Algorithms on the Trauma Register DGU. Critical Care 16: R129

21. Nunez TC, Voskresensky IV, Dossett LA, Shinall R, Dutton WD, et al. (2009). Early Prediction of Massive Transfusion in Trauma: Simple as ABC (assessment of blood consumption)? J Trauma. 66: 346-52. [Crossref]

22. Aintree University Hospital NHS Foundation Trust. Code Red Trauma Standard Operating Procedure. November 2015 (available on request)

23. Weaver AE, Thompson J, Lockey DJ. (2012). The effectiveness of a simple 'Code Red' transfusion request policy initiated by prehospital physicians (2012). Scand J Trauma Resusc Emerg Med 20(S1): O1

24. Weaver AE, Hunter-Dunn C, Lyon RM, Lockey D, Krogh CL (2016) The effectiveness of a 'Code Red' transfusion request policy initiated by pre-hospital physicians. Injury 47: 3-6. [Crossref]

25. Reed MJ, Glover A, Byrne L, Donald M, McMahon N, et al. (2017) Experience of implementing a National pre-hospital Code Red bleeding protocol in Scotland. Injury 48: 41-46. [Crossref]

26. Holcomb JB, Tilley BC, Baraniuk S, Fox EE, Wade CE, et al. (2015). Transfusion of Plasma, Platelets, and Red Blood Cells in a 1:1:1 vs a 1:1:2 Ratio and Mortality in Patients with Severe Trauma. JAMA 313, 471. [Crossref]

27. Horne S, Smith JE (2011) Preparation of the resuscitation room and patient reception. $J$ R Army Med Corps 157: S267-272. [Crossref]
28. Mercer SJ, Arul GS, Pugh HEJ, et al. (2014). Performance Improvement Through Best Practice Team Management - Human Factors in Complex Trauma. J R Army Med Corps 160, 105-8. [Crossref]

29. Smith JE, Russell R, Horne S. (2011). Critical Decision-making and Timelines in the Emergency Department. J R Army Med Corps 157: S273-S276. [Crossref]

30. NHS Blood \& Transplant. Available at: www.blood.co.uk/news-and-campaigns/thedonor-magazine-summer-2017/blood-group-basics/ (accessed 22 February 2018)

31. Jones CP, Keene DD, Nordman GR. (2017). Viscoelastic testing of coagulation. International Anaesthesiology Clinics. 55, 96-108

32. Schochl H, Cotton B, Inaba K, Nienaber U, Fischer H et al. (2011). FIBTEM provides early prediction of massive transfusion in trauma. Crit Care. 15, R265. [Crossref]

33. Theusinger OM, Spahn DR, Ganter MT (2009) Transfusion in trauma: why and how should we change our current practice? Curr Opin Anaesthesiol 22: 305-312. [Crossref]

34. North West Regional Transfusion Committee Audit of Major Haemorrhage in Trauma. May - July 2014. Available at: www.transfusionguidelines.org/uk-transfusioncommittees/regional-transfusion-committees/audits/audits/north-west-rtc-audit-ofmajor-haemorrhage-in-trauma-may-july-2014 (accessed 22 February 2018)

35. Curry S, Hemmatapour M, Lawn C et al. (2012). Are Major Haemorrhage Protocols Effective? An Audit of 4 Major Trauma Centres. Transfusion Medicine. 22, 13

36. Endsley MR. (1995). Toward a Theory of Situation Awareness in Dynamic Systems Human Factors. 37, 32-64.

37. Fadden S, Mercer SJ. (2018). Followership in Complex Trauma. Trauma (In Press).

38. Frank M, Schmucker U, Stengel D, Fischer L, Lange J, et al. (2010) Proper estimation of blood loss on scene of trauma: tool or tale? J Trauma 69: 1191-1195. [Crossref]

39. Berry C, Ley EJ, Bukur M, Malinoski D, Margulies DR, et al. (2012) Redefining hypotension in traumatic brain injury. Injury 43: 1833-1837. [Crossref]

40. Fuller G, Hasler RM, Mealing N, Lawrence T, Woodford M, et al. (2014) The association between admission systolic blood pressure and mortality in significant traumatic brain injury: a multi-centre cohort study. Injury 45: 612-617. [Crossref]

41. Manley G, Knudson MM, Morabito D, Damron S, Erickson V, et al. (2001) Hypotension, hypoxia, and head injury: frequency, duration, and consequences. Arch Surg 136: 1118-1123. [Crossref]

42. Arul GS, Pugh HEJ, Mercer SJ, Midwinter MJ. (2012). Optimising Communication in the Damage Control Resuscitation- Damage Control Surgery Sequence in Major Trauma Management. J R Army Med Corps 158, 82-84. [Crossref]

43. Body R, Cook G, Burrows G, Carley S, Lewis PS (2014). Can Emergency Physicians 'Rule In' and 'Rule Out' Acute Myocardial Infarction with Clinical Judgement? Emerg Med J31, 872-876. [Crossref]

44. Alberdi F, García I, Atutxa L, Zabarte M (2014) Trauma and Neurointensive Care Work Group of the SEMICYUC Epidemiology of severe trauma. Med Intensiva 38: 580-588. [Crossref]

Copyright: (C2018 Morton S. This is an open-access article distributed under the terms of the Creative Commons Attribution License, which permits unrestricted use, distribution, and reproduction in any medium, provided the original author and source are credited. 